\title{
Eosinophil chemotaxis of supernatants from cultured Hodgkin's lymph node cells
}

\author{
A. B. KAY, J. G. McVIE, A. E. STUART, A. KRAJEWSKI, AND \\ LINDSAY W. TURNBULL \\ From the South-East Scotland Regional Blood Transfusion Service, Royal Infirmary of Edinburgh, and \\ the University Departments of Respiratory Diseases, Therapeutics, and Pathology
}

SYNOPSIS Cultured lymph node cell supernatants from five out of six cases of Hodgkin's disease were relatively more chemotactic for peripheral blood eosinophils than neutrophils. In contrast, supernatants from two cases of lymphocytic lymphoma and four nodes showing reactive hyperplasia were chemotactic for neutrophils but had little eosinophil chemotactic activity. In most instances the degree of eosinophil infiltration observed histologically in the Hodgkin's lymph node correlated with elaboration of eosinophil chemotactic activity from the cultured cells. Following gel-filtration of three of the Hodgkin's lymph node supernatants, four peaks of eosinophil chemotactic activity were demonstrated in each case. One of these corresponded in molecular size to the previously described eosinophil chemotactic factor of anaphylaxis (ECF-A). It is suggested that the eosinophil chemotactic activity of cultured lymph node cell supernatants may be of value in the diagnosis and classification of Hodgkin's disease.

The histological diagnosis of Hodgkin's disease is made by the recognition of the characteristic ReedSternberg cell which is a large multinucleate cell containing two or more nuclei with prominent nucleoli (Butler, 1970). Other morphological features of the lymph nodes are variable, and this has led to several attempts at classification with the object of relating the histology to clinical staging and prognosis (Jackson and Parker, 1944a; Jackson and Parker, 1944b; Lukes and Butler, 1966; Smithers, 1967; Smithers, 1970; Dorfman, 1972). One of the characteristics of the Hodgkin's lymph node is the presence of eosinophil leucocytes (Dreschfeld, 1892), and it has been suggested that this may represent part of the inflammatory infiltrate (Stuart, 1970), the eosinophil accumulation in the nodes being a result of chemotaxis (Vianna et al, 1971). In the present study we provide evidence to support this concept by showing that supernatants from cultured Hodgkin's lymph nodes attract a greater proportion of eosinophils from mixed leucocyte populations than do supernatants from cultures of nonHodgkin's lymph nodes.

Received for publication 15 January 1975.

\section{Material and Methods}

PREPARATION OF LYMPH NODE CELL

CULTURE SUPERNATANTS

Lymph nodes obtained at surgery were bisected. One-half was taken for routine histology and the other for cell culture as described (Habeshaw, 1972). Cells for culture were obtained by carefully dividing the tissue into small fragments with scalpel blades, gently homogenizing and passing through a sieve to remove fibrous debris. Cell counts were adjusted to $5 \times 10^{6} \mathrm{cells} / \mathrm{ml}$ and the viability was assessed by Trypan blue exclusion and phase contrast microscopy. Only those preparations which contained greater than $90 \%$ of viable cells were subsequently cultured. Cultures were set up in 'flying cover slips' in glass test tubes, and the cells were contained in $1 \mathrm{ml}$ volumes of medium 199 with $0.5 \%$ lactalbumin, 50 units of penicillin, and $5 \mu \mathrm{g}$ of streptomycin. The tubes were incubated at $37^{\circ} \mathrm{C}$ and the supernatants removed at day 3 , replaced with culture medium, and removed again at day 5 . Supernatants thus obtained were centrifuged to $\varrho$ remove particulate material, pooled and dialysed for 24 hours against phosphate buffered saline (PBS), \& and lyophilized. Before chemotaxis the material 
was reconstituted in distilled water and the protein concentrations were measured by the FolinCiolcalteau method.

\section{MEASUREMENT OF CHEMOTAXIS}

Chemotaxis of human peripheral blood eosinophils and neutrophils was assayed by a modification of the Millipore technique of Boyden as previously described (Kay, 1970). Cell counts were performed in duplicate or triplicate. A chemotactic index to show the relative proportion of eosinophils migrating was calculated from the equation:

Eosinophil chemotactic count/

Neutrophil chemotactic count

\begin{abstract}
$\%$ eosinophils in cell suspension before migration/
$\%$ neutrophils in cell suspension before migration
\end{abstract}

GEL FILTRATION

Hodgkin's lymph node cell supernatants were concentrated by rotary evaporation at $37^{\circ} \mathrm{C}$ under vacuum. Samples of $1 \mathrm{ml}$ containing approximately $11.5 \mathrm{mg} / \mathrm{ml}$ of protein were applied to a column of Sephadex G-50 $(104 \times 2.5 \mathrm{~cm})$ in PBS. From alternate $2 \mathrm{ml}$ fractions $0.5 \mathrm{ml}$ volumes were taken and tested in duplicate for neutrophil and eosinophil chemotaxis.

\section{Results}

Chemotactic activity from cultured lymph node cell supernatants was demonstrable in a dose-dependent fashion as shown in fig 1 for cultures from a Hodgkin's and a reactive lymph node cell supernatant.

The chemotactic activity of lymph node cell supernatants from six patients with Hodgkin's disease, two with lymphocytic lymphoma, and four

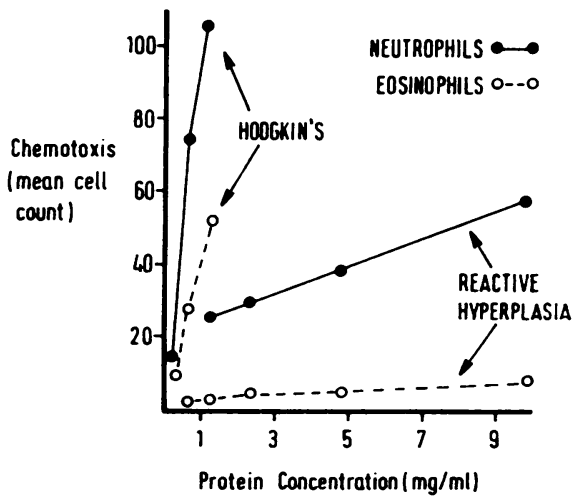

Fig 1 Neutrophil and eosinophil chemotactic activity of a Hodgkin's and reactive hyperplasia cultured lymph node cell supernatant. nodes showing reactive hyperplasia are shown (fig 2). Neutrophil and eosinophil chemotaxis was demonstrable with all supernatants but five out of the six Hodgkin's supernatants gave greater eosinophil chemotactic indices than the highest index obtained with non-Hodgkin's supernatants.

The degree of eosinophil infiltration in the lymph nodes, arbitrarily assessed 0 to ++ , to some extent correlated with the eosinophil chemotactic activity from the cell culture supernatants (fig 2). However, one Hodgkin's node had no eosinophils, and eosinophil infiltration was present in one of the nonHodgkin's nodes.

When the chemotactic gradient was eliminated by placing supernatants from either Hodgkin's or nonHodgkin's lymph nodes in both the test and cell compartments of the chemotactic chambers little or no migration was observed for either cell type. This suggests that the leucotaxis was a result of directional, rather than random, migration.

When concentrated cell supernatants from three Hodgkin's lymph nodes were applied to a column of Sephadex G-50 four peaks of eosinophil chemotactic

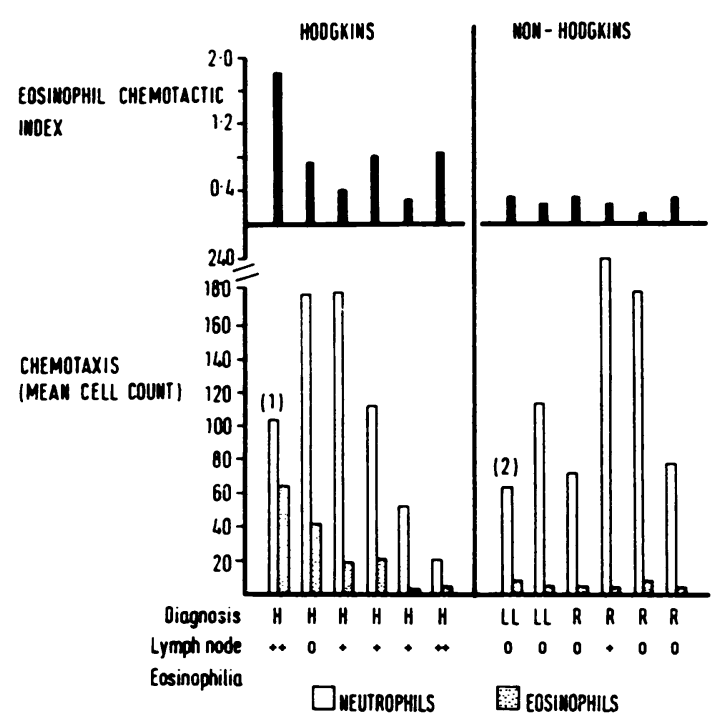

Fig 2 Neutrophil and eosinophil chemotaxis and the eosinophil chemotactic index from Hodgkin's and nonHodgkin's cultured lymph node cell supernatants. The degree of lymph node eosinophil infiltration is also indicated: $H=H o d g k i n ' s$ disease, $L L=$ lymphocytic lymphoma, $R=$ reactive hyperplasia. The measurements represent the pooled results from three experiments except in (1) and (2) where there was sufficient sample for only one and two estimations respectively. All samples were tested at a protein concentration of $0.6 \mathrm{mg} / \mathrm{ml}$. 


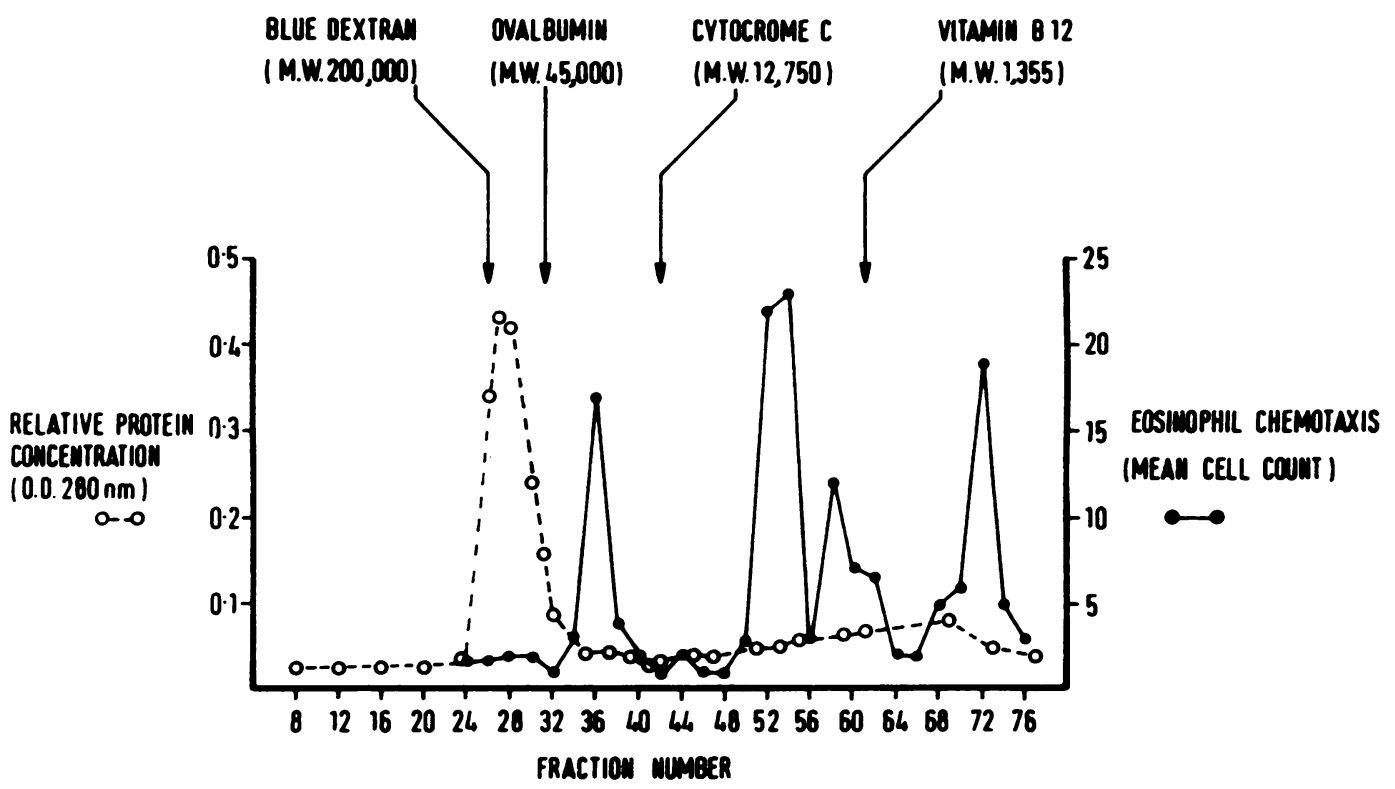

Fig 3 Sephadex G-50 chromatography of a cultured lymph node cell supernatant from Hodgkin's disease. The column was previously calibrated with markers having the molecular sizes indicated.

activity were consistently demonstrable (fig 3 ). The molecular markers indicated that these four activities were associated with molecules having an approximate molecular size of $30000,6000,2000$, and 500 daltons respectively (fig 3 ).

\section{Discussion}

The capacity of human peripheral blood lymphocytes to release chemotactic factors for neutrophils and monocytes following stimulation by mitogens and specific antigen has been reported by a number of workers (Ward et al, 1969; Altman et al, 1973). In addition, an eosinophil chemotactic factor from lymphocyte supernatants has also been reported, but in this system there was an additional requirement for antigen-antibody complexes (Cohen and Ward, 1971). In the present study we have demonstrated the elaboration of neutrophil and eosinophil chemotactic agents from cultured lymph node cell supernatants but in addition have shown that Hodgkin's lymph node preparations attract relatively more eosinophils than the non-Hodgkin's supernatants (figs 1 and 2).

Care was taken to use the same protein concentrations when making comparisons between the activity of the cell supernatants. A dose-response effect was obtained with each supernatant as well as the ones depicted in figure 1.
Although relatively more eosinophil than neutrophil chemotactic activity was observed in a node in which histologically there were no demonstrable eosinophils, there was in general an association between lymph node eosinophilia and the elaboration of eosinophil chemotactic activity. More direct evidence would be possible by performing these measurements on several nodes from individual patients.

Several peaks of activity were obtained following chromatography on Sephadex G-50, suggesting that there is a heterogeneity of eosinophil chemotactic factors from Hodgkin's lymph node cell supernatants(fig 3). One peak corresponded to a molecular size of the eosinophil chemotactic factor of anaphylaxis (ECF-A) (Kay and Austen, 1971; Kay et al, 1971). In a previous report a substance of compatible molecular size was extracted from an undifferentiated carcinoma of lung associated with a peripheral blood eosinophilia (Wasserman et al, 1974).

The finding that Hodgkin's lymph node cell supernatants attract relatively more eosinophils than non-Hodgkin's cultures suggests that this may be of value both in diagnosis and in the classification of various forms of the disease.

This work was supported by a grant from the Melville Trust, the Medical Research Council, the Cancer Campaign, and an anonymous gift to the 
Department of Respiratory Diseases, University of Edinburgh. We are very grateful to $\mathrm{Dr}$ R. A. A. Macaulay, Department of Pathology, University of Edinburgh, for diagnosing the histological sections.

\section{References}

Altman, L. C., Snyderman, R., Oppenheim, J. J., and Mergenhagen, S. E. (1973). A human mononuclear leukocyte chemotactic factor: characterization, specificity and kinetics of production by homologous leukocytes. $J$. Immunol., 110, 801-810.

Butler, J. J. (1970). Histopathology of malignant lymphomas and Hodgkin's disease In Leukemia-lymphoma (14th Annual Clinical Conference on Cancer), 1969, p. 123. Year Book Medical Publishers, Chicago.

Cohen, S. and Ward, P. A. (1971). In vitro and in vivo activity of a lymphocyte and immune complex-dependent chemotactic factor for eosinophils. J. exp. Med., 133, 133146.

Dorfman, R. F. (1972). Biology of malignant neoplasia of the lymphoreticular tissues. J. Reticuloendoth. Soc., 12, 239-256.

Dreschfeld, J. (1892). Clinical lecture on acute Hodgkin's disease. Brit. med. J., 1, 893-896.

Habeshaw, J. (1972). A serum-protein-free medium for the culture of macrophages and related cells. J. Path., 108, 95 96.

Jackson, H., Jr., and Parker, F., Jr. (1944a). Hodgkin's disease I. General considerations. New Engl. J. Med., 230, 1-8.

Jackson, H., Jr., and Parker, F., Jr. (1944b). Hodgkin's disease II. Pathology. New Engl. J. Med., 231, 35-44.

Kay, A. B. (1970). Studies on eosinophil leucocyte migration II. Factors specifically chemotactic for eosinophils and neutrophils generated from guinea-pig serum by antigenantibody complexes. Clin. exp. Immunol., 7, 723-737.

Kay, A. B. and Austen, K. F. (1971). The IgE-mediated release of an eosinophil leucocyte chemotactic factor from human lung. J. Immunol., 107, 899-902.

Kay, A. B., Stechschulte, D. J., and Austen, K. F. (1971). An eosinophil leukocyte chemotactic factor of anaphylaxis. J. exp. Med., 133, 602-619.

Lukes, R. J. and Butler, J. J. (1966). The pathology and nomenclature of Hodgkin's disease. Cancer Res., 26, 1063-1081.

Smithers, D. W. (1967). Hodgkin's disease I. Brit. med. J., 2, 263-268.

Smithers, D. W. (1970). Hodgkin's disease: one entity or two? Lancet, $2,1285-1288$.

Stuart, A. E. (1970). Immunological aspects of reticulum cell neoplasia. Brit. med. J., 4, 423-424.

Vianna, N. J., Greenwald, P., and Davies, J. N. P. (1971). Nature of the Hodgkin's disease agent. Lancet, 1, 733-736.

Ward, P. A., Remold, H. G., and David, J. R. (1969). Leukotactic factor produced by sensitized lymphocytes. Science, 163, 1079-1081.

Wasserman, S. I., Goetzl, E. J., Ellman, L., and Austen, K. F. (1974). Tumor-associated eosinophilotactic factor. New Engl. J. Med., 290, 420-424. 